Rov. Fac. Med. vet. Zootec. Univ. S. Paulo

$12: 277-82,1975$

\title{
TOXOPLASMOSE EM EQUINOS PSI. ESTUDO SOROLÓGICO
}

\author{
Romeu MACRUZ * \\ Oswaldo LENCI * \\ Masaio Mizuno ISHIZUKA ** \\ Omar MIGUEL ** \\ Regina Ayr F. da CUNHA ***
}

RFMV-A/27

Macruz, R.; Lenci, O.; Ishizuka, M. M.; Miguel, 0.; Cunha, R. A. da - Toxoplasmose em eqüinos PSI. Estudo sorológico. Rev. Fac. Med. vet. Zootec. Univ. S. Paulo, 12:277-82, 1975.

Resumo: Setenta e sete eqüinos PSI do Estado de São Paulo, com diagnóstico clínico de toxoplasmose e sadios, foram divididos nos seguintes grupos de acordo com a sintomatologia observada:

1) incoordenaçāo motora (24 animais);

2) com história passada de pelo menos 1 (hum) aborto; (2s casos);

3) irritabilidade excessiva (5 casos);

4) clinicamente sadios (25).

Examinados pelo teste de Sabin-Feldman, todos 0852 soros dos três primeiros grupos (doentes) apresentaram apreciáveis niveis de anticorpos anti-toxoplasma que variaram de 64 a 4000 , sendo o valor 1000 o mais freqüente; dentre os animais clinicamente sadios, somente 1 (5\%) foi reagente ao título 16.

Os resultados sugerem ter sido a toxoplasmose recenten zente introduzida no rebanho eqüino.

UNITERMos: Toxoplasmose*; Sabin-Feldman*; Eqüinos*.

\section{I N T K O D U C $\mathbb{A}$ O}

A toxoplasmose é uma zoonose que vem merecendo destaque cada vez maior, pois, se no homem as lesões provocadas principalmente na sua forma congênita de transmissão, são irreversíveis (FREN-
$\mathrm{KEL}^{3}$, 1971) nos animais há que se distinguir dois aspectos de primordial importância: de um lado as elevadas perdas ecomômicas que a doença provoca, principalmer,te, em rebanhos suínos, ovinos e capri-

- Médico Veterinário do Jockey Club de Sāo Paulo.

*. Professor Assistente Doutor.

Departamento de Medicina Veterinária Preventiva e Saúde Animal da Faculdade de Medicina Veterinária e Zootecnia da U.S.P.

*. Técnica de Laboratório.

Divisão de Assistência Veterinária do Jockey Club de Sāo Paulo. 
MACRUZ, R.; LENCI, O.; IShIZUKA, M. M.; MIGUEL, O.; CUNHA, R. A. da - Toxoplasmose em eqüinos PSI. Estudo sorológico. Rev. Fac. Med. vet. Zootec. Univ. S. Paulo, 12 : $277-82,1975$.

nos, traduzidas por aborto e nascimento de fetos de baixa viabilidade e por outro lado, os animais de estimação e domésticos acometidos de infecção aguda ou crônica, podem representar importantes fontes de infecção para o homem, (NOBUTO \& TSUTSUMI ${ }^{6}$, 1973). Muito embora, esta última citação seja profundamente minuciosa em abordar a doença nos animais, tivemos a oportunidade de verificar que a espécie eqüina nāo é mencionada. Já, SIIM, (1963), relata apenas um levantamento sorológico em eqüinos aparentemente sadios, com base aos resultados da prova de Fixação de Complemento. MC DONALD et al.4, $(1969 / 70)$, descrevem clinicamente o caso de um eqüino que apresentou cegueira, ataxia e incoordenação motora, cujo resultado da reação de Sabin - Feldman foi de 1:16.

CUSICK $^{1}$ (1974) descreve a toxoplasmose em dois eqüinos que manifestaram ataxia e incoordenação dos membros posteriores e os exames histopatológicos revelaram a presença de $T$. gondii no tecido nervoso.

DUBEY ${ }^{2}$, (1974) descreve o quadro clínico de quatro equiinos suspeitos de toxoplasmose que manifestaram principalmente incoordenação motora dos membros posteriores, cabeça inclinada para um dos lados e o andar em círculo dentro da cachoeira; aos exames histopatológicos o autor observou a presença de protozoários semelhante ao $T$. gondii.

Desde há alguns meses, tem surgido entre equiinos PSI do Estado de São Paulo, casos clínicos caracterizados por incoordenação motora, às vezes associada ao andar em círculo no interior do box, abortamento e irritabilidade excessiva, sugerindo tratar-se de toxoplasmose, uma vez que outras causas foram eliminadas. Baseados neste fato, resolvemos realizar um inquérito sorológico naqueles animais clinicamente afetados para fins de verificação de uma possível alteração nos níveis de anticorpos anti-toxoplasma e se o agente etiológico foi introduzido pela primeira vez na população de eqüinos PSI, espera-se que todos os infectados tenham adoecido e portanto, apresentem anticorpos anti-toxoplasma na circulação e nenhum dos não doentes apresentem anticorpos séricos.

\section{MATERIAL E MÉTODOS}

1) Grupos experimentais:

Grupo $I$ - constituído de 24 eqüinos dos quais 2 manifestaram incoordenação motora dos membros anteriores e 22 dos membros posteriores, associada ao movimento de andar em círculo no interior do box;

Grupo $I I$ - constituído de 23 éguas com história passada de pelo menos um aborto;

Grcpo III - constituído de 5 animais apresentando irritabilidade excessiva;

Grupo IV - constituído de 25 animais clinicamente sadios, mantido como grupo testemunha e tomamos o cuidado de incluir, neste rupo, 7 éguas com história passada de partos sucessivos sem aborto.

2) Coleta de material:

Amostras de sangue, em volume de 10 $\mathrm{ml}$, foram coletadas por punção da veia jugular, em tubos de centrífuga. Após a coagulação do sangue procedeu-se à centrifugação a $1500 \mathrm{rpm}$., por 15 minutos, para fins de retração do coágulo e separação dos soros. Estes foram coletados com o auxílio de pipeta Pasteur, condicionados em frascos apropriados e mantidos em congelador a $-15 .{ }^{\circ} \mathrm{C}$, até o momento da realização da prova.

3) Método sorológico:

Os soros sangüíneos foram submetidos à prova Sabin-Feldman realizada, segundo SABIN \& FELDMAN ${ }^{7}$ (1948).

\section{4) Método estatistico:}

Utilizamos o coeficiente de Associação de Yule e teste de $\mathrm{X}^{2}$ (Qui-quadrado) calculados segundo MARASCUILLO ${ }^{5}$ (1971). O nível de rejeição adotado foi de $5 \%$.

\section{R E S U L T A D O S}

Inicialmente, apreciamos o comportamento do soro dos animais considerados apenas como reagentes e não reagentes, de acordo com a condição de doentes e não 
MACRUZ, R.; LENCI, O.; ISHIZUKA, M. M.; MIGUEL, O.; CUNHA, R. A. da - Toxoplasmose em eqüinos PSI. Estudo sorológico. Rev. Fac. Med. vet. Zootec. Univ. S. Paulo, 12: $277-82,1975$.

doentes. Consideramos reagentes, os soros dos eqüinos que submetidos à prova de Sabin-Feldman, apresentaram $50 \%$ ou mais de toxoplasmas não corados pelo azul de metileno, à uma diluição de pelo menos $1: 16$. Os resultados encontram-se na $\mathrm{Ta}$ bela I.

O coeficiente de associação de Yule mostrou-se igual a 1, calculado com base aos dados constantes na Tabela I. Ainda, com relação aos resultados desta Tabela, calculamos o valor de $\mathrm{X}^{2}$ que se revelou igual a 69 e quando comparado ao valor crítico de $\mathrm{X}^{2}$ para um grau de liberdade foi significante, em vista de ser bem superior ao valor crítico de $\mathrm{X}^{2}$ (igual a 3,84 ), para o nível de rejeição adotado.

A segunda etapa de nossa análise envolveu a avaliação quantitativa dos resultados, levando-se em consideração o estudo do comportamento dos títulos de anticorpos anti-toxoplasma (recíproca da diluição), segundo a sintomatologia apresentada e tais dados encontram-se na Tabela II.

\section{D I S C U S S Ã 0}

Observando-se a Tabela I, podemos verificar que todos os animais doentes reagiram positivamente ao teste de Sabin-Feldman $(52 / 52)$, sendo que dentre os 25 eqüi- nos ${ }^{*}$ do grupo testemunha apenas $1(1 / 25$ $=5 \%$ ), foi reagente e os restantes negativos. í dispensável qualquer tratamento estatístico para se verificar que há diferença significante na diferença de proporcões de reagentes entre doentes e não doentes. Por outro lado, o valor do coeficiente de associação de Yule, mostrou-se igual a 1 (hum) indicando existir uma relação positiva entre os atributos reagentes $\mathrm{e}$ doentes e o cálculo do $\mathrm{X}^{2}$ revelou que tal relacão era significante ao nível de rejeição adotado.

A Tabela II mostra-nos que dentre os animais com sintomas de toxoplasmose, os títulos de anticorpos anti-toxoplasma variaram de 64 a 4000 e a simples observação desta tabela permite-nos verificar que o título de anticorpos 1000 foi o valor mais freqüente. Além disso, verificamos que dentre os animais do grupo IV (animais sem sintomas), apenas um eqüino reagiu positivamente à prova de Sabin-Feldman a um título igual a 16 .

Tais fatos nos permitem admitir que a sintomatologia observada sugeria fortemente tratar-se de toxoplasmose. 0 fato de todos animais doentes e apenas 5\% dos animais não doentes terem apresentado anticorpos circulares, sugere ter sido a toxoplasmose uma doença de introdução recente no rebanho eqüino.

T A B E L A I

Eqüinos PSI, segundo condiçāo e resultado da prova Sabin-Feldman, Sāo Paulo, 1975.

\begin{tabular}{|c|c|c|c|}
\hline Condição & Reagente & Não reagente & Total \\
\hline Doentes & $52(100 \%)$ & 0 & 52 \\
\hline Não doentes & $1 \quad(5 \%)$ & $24(95 \%)$ & 25 \\
\hline TOTAL & 53 & 24 & 77 \\
\hline
\end{tabular}


MACRUZ, R.; LENCI, O.; ISHIZUKA, M. M.; MIGUEL, O.; CUNHA, R. A. da - Toxoplasmose em eqüinos PSI. Estudo sorológico. Rev. Fac. Med. vet. Zootec. Univ. S. Paulo, 12 : $277-82,1975$.

T A B E L A I I

Eqüinos PSI, segundo títulos de anticorpos antitoxoplasma medidos pela prova de Sabin-Feldman e sintomas apresentados, São Paulo, 1975.

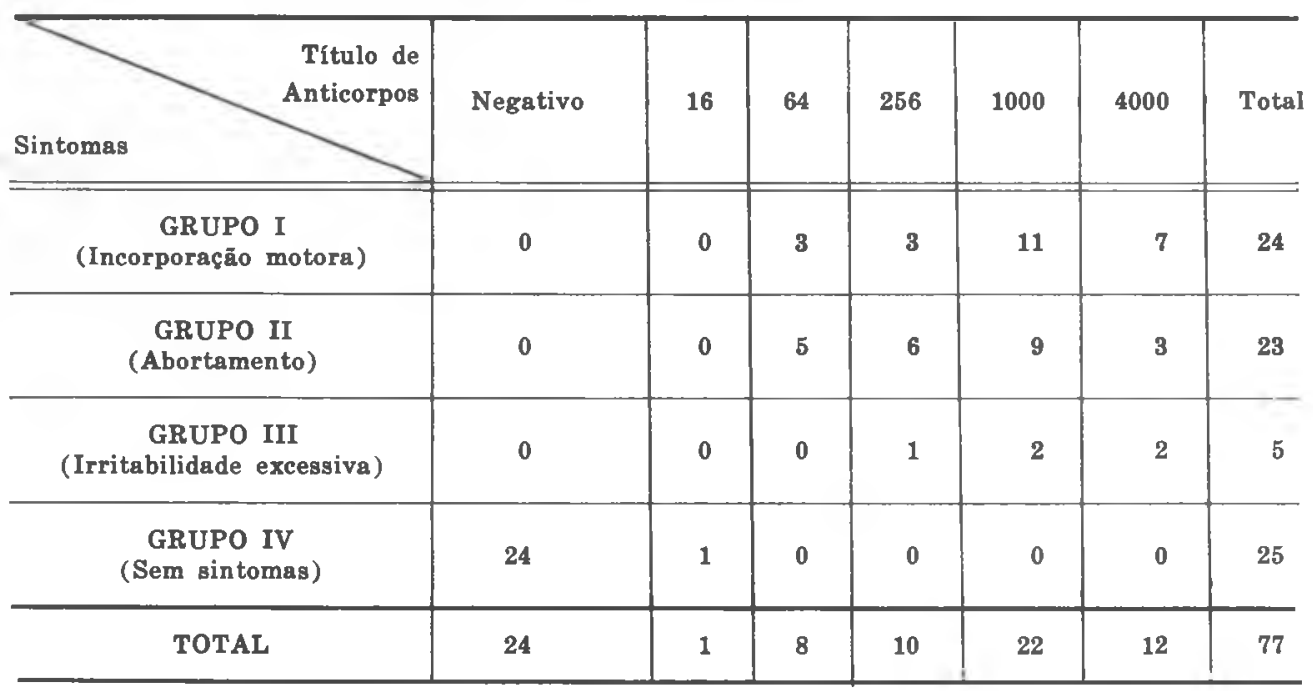

RFMV-A/27

Macruz, R.; Lenci, O.; Ishizuka, M. M.; Miguel, O.; Cunha, R. A. da - Toxoplasmosis in the equine. Serelogical evaluation. Rev. Fac. Med. vet. Zootec. Univ. S. Paulo, 12:277-82, 1975.

SUMMARY: Seventy seven throughbred horses of São Paulo state, among them 52 attacked by toxoplasmosis and 25 normals, were grouped according to the observed signs:

1) with incoordination (24 animals);

2) females that suffered, in the past, at least one abortion (23 ani mals) ;

5) excessive irritability (5 animals);

4) without signs (25 animals).

Blood samples of all animals were examined by the Sabin-Feldman test and all 52 sick animals were positive and the antibody titer varied from 64 to 4000 and more frequent value of the antibody level was 1000 . Among the animals of the control group, 24 serum specimens were negative and one was positive at the $1: 16$ dilution.

The results suggest that the infection by the Toxoplasma gondii was recently introduced in horse population.

UNITERMS: Toxoplasmosis*; Sabin-Feldman*; Equine*. 
MACRUZ, R.; LENCI, O.; ISHIZUKA, M. M.; MIGUEL, O.; CUNHA, R. A. da - Toxoplasmose em eqüinos PSI. Estudo sorológico. Rev. Fac. Med. vet. Zootec. Univ. S. Paulo, 12: 277-82, 1975 .

\section{REFERENCIAS BIBLIOGRAFICAS}

1. CUSIK, P. K. - Toxoplasmosis in two horses. J. Amer. vet. med. As8., 164 (1) :77-80, 1974.

2. DUBEY, J. P. - Equine encephalomyelitis due to a protozan parasiteresembling Toxoplasma gondii. J. Amer. vet. med. As8., 165 (3) :249-55, 1974.

3. FRENKEL, J. K. - Toxoplasmosis-mechanisms of infection, laboratory diagnosis and management. Curr. top. Patr., $54: 28-75,1971$.

4. McDONALD, D. R et al. - Toxoplasmosis in the equine. Swest. Vet., 23:213 14, 1969-70.

5. MARASCUILLO, L. A. - Statistical methods for behavioral science research. New York, McGraw-Hill, 1971.
6. NOBUTO, K. \& TSUTSUMI, Y. - Saikin ni okeru toxoplasmosis sho, sono tishiki to shindan. Tokio, Chuwa-Tokyo, 1974.

7. SABIN, A. B. \& FELDMAN, H. A. Dyes as microchemical indicators of a new immunity phenomenon affecting a protozoan parasite (Toxoplasma). Science, 108:660, 1948.

8. SIIM, J. C. - Toxoplasmosis in domestic animals. Advanc. vet. Sci., 8:335-429, 1963.

Recebido para publicação em 29-8-75

Aprovado para publicação em 17-9-75 